Article

\title{
Long Non-Coding RNA Malat1 Regulates Angiogenesis in Hindlimb Ischemia
}

\author{
Xuejing Zhang ${ }^{1}{ }^{(1)}$, Xuelian Tang ${ }^{1}$, Milton H. Hamblin ${ }^{2}$ and Ke-Jie Yin ${ }^{1, *(1)}$ \\ 1 Pittsburgh Institute of Brain Disorders \& Recovery, Department of Neurology, University of Pittsburgh \\ School of Medicine, Pittsburgh, PA 15213, USA; xuz20@pitt.edu (X.Z.); xut5@pitt.edu (X.T.) \\ 2 Department of Pharmacology, Tulane University School of Medicine, 1430 Tulane Avenue SL83, \\ New Orleans, LA 70112, USA; mhambli@tulane.edu \\ * Correspondence: yink2@upmc.edu; Tel.: +1-412-383-6038
}

Received: 3 May 2018; Accepted: 5 June 2018; Published: 11 June 2018

\begin{abstract}
Angiogenesis is a complex process that depends on the delicate regulation of gene expression. Dysregulation of transcription during angiogenesis often leads to various human diseases. Emerging evidence has recently begun to show that long non-coding RNAs (lncRNAs) may mediate angiogenesis in both physiological and pathological conditions; concurrently, underlying molecular mechanisms are largely unexplored. Previously, our lab identified metastasis associates lung adenocarcinoma transcript 1 (Malat1) as an oxygen-glucose deprivation (OGD)-responsive endothelial lncRNA. Here we reported that genetic deficiency of Malat1 leads to reduced blood vessel formation and local blood flow perfusion in mouse hind limbs at one to four weeks after hindlimb ischemia. Malat1 and vascular endothelial growth factor receptor 2 (VEGFR2) levels were found to be increased in both cultured mouse primary skeletal muscle microvascular endothelial cells (SMMECs) after $16 \mathrm{~h}$ OGD followed by $24 \mathrm{~h}$ reperfusion and in mouse gastrocnemius muscle that underwent hindlimb ischemia followed by 28 days of reperfusion. Moreover, Malat1 silencing by locked nucleic acid (LNA)-GapmeRs significantly reduced tube formation, cell migration, and cell proliferation in SMMEC cultures. Mechanistically, RNA subcellular isolation and RNA-immunoprecipitation experiments demonstrate that Malat1 directly targets VEGFR2 to facilitate angiogenesis. The results suggest that Malat1 regulates cell-autonomous angiogenesis through direct regulation of VEGFR2.
\end{abstract}

Keywords: long non-coding RNA; Malat1; angiogenesis; vascular endothelial cells; VEGFR2; hindlimb ischemia

\section{Introduction}

Angiogenesis, mainly stimulated by hypoxia in ischemic tissue, refers to the growth of new capillary blood vessels from the pre-existing vasculature. The formation process of new angiogenic vessels involve the proliferation, migration, and differentiation of blood vascular endothelial cells (ECs) [1]. Angiogenesis plays pivotal physiological functions in embryonic development, wound repair, tissue engineering, and placental development [1]. However, when dysregulated, the formation of new blood vessels may contribute to numerous oncogenic, ischemic, infectious, and inflammatory diseases [1-3]. At present, both anti- and pro-angiogenic treatments have therapeutic implications in human diseases [4]. For example, inhibition of angiogenesis can be beneficial in disorders such as cancer, arthritis, psoriasis, ophthalmic conditions, and hemangioma, whereas stimulation of angiogenesis can be beneficial in disorders such as ischemic stroke, ischemic heart disease, placental insufficiency, and other ischemia-associated diseases [4-6].

Importantly, the angiogenic response is strictly controlled by a coordinated regulation of both pro-angiogenic and anti-angiogenic molecules [7]. Dysregulation of transcription during this process 
favors pathological angiogenesis and accumulates endogenous pro-angiogenic molecules including growth factors, matrix metalloproteinases (MMPs), cytokines, and integrins $[8,9]$. Specifically, the major signaling molecule for angiogenesis is vascular endothelial growth factor (VEGF) which is commonly found to be upregulated in pathological conditions such as cancer and ischemic diseases $[10,11]$. VEGF promotes endothelial cell survival, proliferation, migration, and differentiation. Hypoxia induces VEGF expression via hypoxia inducible factor $1 \alpha$ (HIF- $1 \alpha)$, which, in turn, activates VEGF receptor 2 (VEGFR2) to stimulate tip cell migration from arteries to initiate angiogenesis [12]. VEGFR2 is known as the major mediator of angiogenic signaling in blood vascular endothelial cells and is required for angiogenesis [13].

LncRNAs are RNA transcripts with no protein-coding ability that are more than 200 nucleotides in length [14]. Advances in whole genome transcriptomic analysis have revealed that large number of IncRNAs are involved in various biological activities, such as cell proliferation [15], muscle differentiation [16], organogenesis [17], chromatin remodeling [18], and genomic imprinting [19]. Previous studies have elucidated the importance of small non-coding RNAs, such as microRNA, in the regulation of angiogenesis [20,21]. However, only a few lncRNAs have been shown to contribute to vascular disease and endothelial cell integrity. Recent evidence indicates that lncRNA can regulate different processes involved in angiogenesis through direct or indirect mechanisms, mainly by regulating angiogenic molecules such as VEGF [22-25]. For example, lncRNA MEG3 knockout mouse presented increased expression of VEGF pathway genes and increased cortical microvessel density by qPCR analysis and immunohistological staining [22]. Another well-studied lncRNA HOTAIR was reported to promote angiogenesis through activating VEGFA transcription in both in vitro and in vivo nasopharyngeal carcinoma studies [23]. LncRNA Punisher has been identified in endothelial cell differentiation and angiogenesis by RNA-sequencing study, and inhibition of Punisher resulted in defective branching and compromised vessel formation [24]. In a recent study, silencing of lncRNA MANTIS inhibited angiogenic sprouting of HUVECs and the alignment of endothelial cells in response to shear stress [25]. Of note, the effects of these lncRNAs on endothelial cell biology and angiogenesis have been identified in both cultured endothelial cells and in ischemia-induced angiogenesis.

Malat1 is one of the most extensively studied lncRNAs that is associated with human diseases [26]. Malat 1 gene is located within human chromosome 11q13 and mouse chromosome 19qA [27]. It is abundantly expressed at a level comparable with or even higher than many protein-coding genes, including $\beta$-actin or glyceraldehyde 3-phosphate dehydrogenase (GAPDH) [28]. Since its discovery, accumulating data from various basic and clinical studies have provided insights into its biogenesis, cellular, and molecular functions. Previously, we and others have demonstrated that Malat 1 can be significantly upregulated by oxygen-glucose deprivation (OGD), hypoxia, and hyperglycemia in endothelial cells [29-31]. Additionally, recent studies have shown that mice with genetic deletion of Malat1 presented reduced retinal vascular growth and endothelial proliferation [32]. Moreover, pharmacological inhibition of Malat1 using locked nucleic acid (LNA)-GapmeRs (single-stranded oligonucleotides designed to specifically silence Malat1) significantly decreased blood flow recovery and capillary density after hindlimb ischemia by impairing the expression of several cell cycle regulators [32]. However, whether Malat1 can regulate cell autonomous angiogenesis in mouse vascular endothelial cells, especially during in vivo settings, remains unexplored.

In the present study, we utilized the Malat1-deficient mice model to explore the effects and molecular mechanisms of Malat1 on hindlimb ischemia-induced angiogenesis. Laser Doppler imaging and capillary density analysis indicated that genetic deletion of Malat 1 significantly inhibited blood flow recovery and capillary density in gastrocnemius muscle tissue after hind limb ischemia. Furthermore, in vitro study confirmed that silencing of Malat1 by LNA-GapmeRs inhibited proliferation, wound closure, and tube formation of mouse primary skeletal muscle microvascular endothelial cells (SMMECs). The mechanism of action for mediating these effects involved Malat1 direct binding and regulating of VEGFR2. Collectively, these results suggest that Malat1 may play critical vascular regulatory roles in promoting angiogenesis. 


\section{Results}

\subsection{Reduction of Local Blood Flow and Vascular Density in Malat1-Deficient Mice after Hindlimb Ischemia}

To define the function of Malat1 in vivo, we employed a silencing strategy using Malat1 knockout (KO) mice on a C57BL/6J background [28]. Malat1 KO and littermate control (WT) mice were subjected to hindlimb ischemia by femoral artery ligation. Local blood flow and capillary density in response to ischemic injury were determined by a laser speckle imager (Perimed PeriCam PSI HR, Stockholm, Sweden) (LSI) and CD31 immunofluorescence staining. In comparison with Malat1 WT mice, recovery of blood flow in ischemic limbs was significantly delayed in Malat1 KO mice at days 7, 21, and 28 after ischemia (Figure 1A,B). Representative CD31 staining images of the sham and ischemic hindlimb muscle in both Malat1 WT and Malat1 KO groups at postoperative day 28 are shown in Figure 1C. The number of capillaries in ischemic hindlimbs was dramatically reduced in Malat1 KO mice compared with Malat1 WT controls (Figure 1D), suggesting that Malat1 may play functional roles in pro-angiogenesis after surgical induction of hindlimb ischemia. Of note, genetic deletion of Malat1 in mice had no effects on local blood flow and capillary density under non-ischemic conditions (Figure 1A-D).
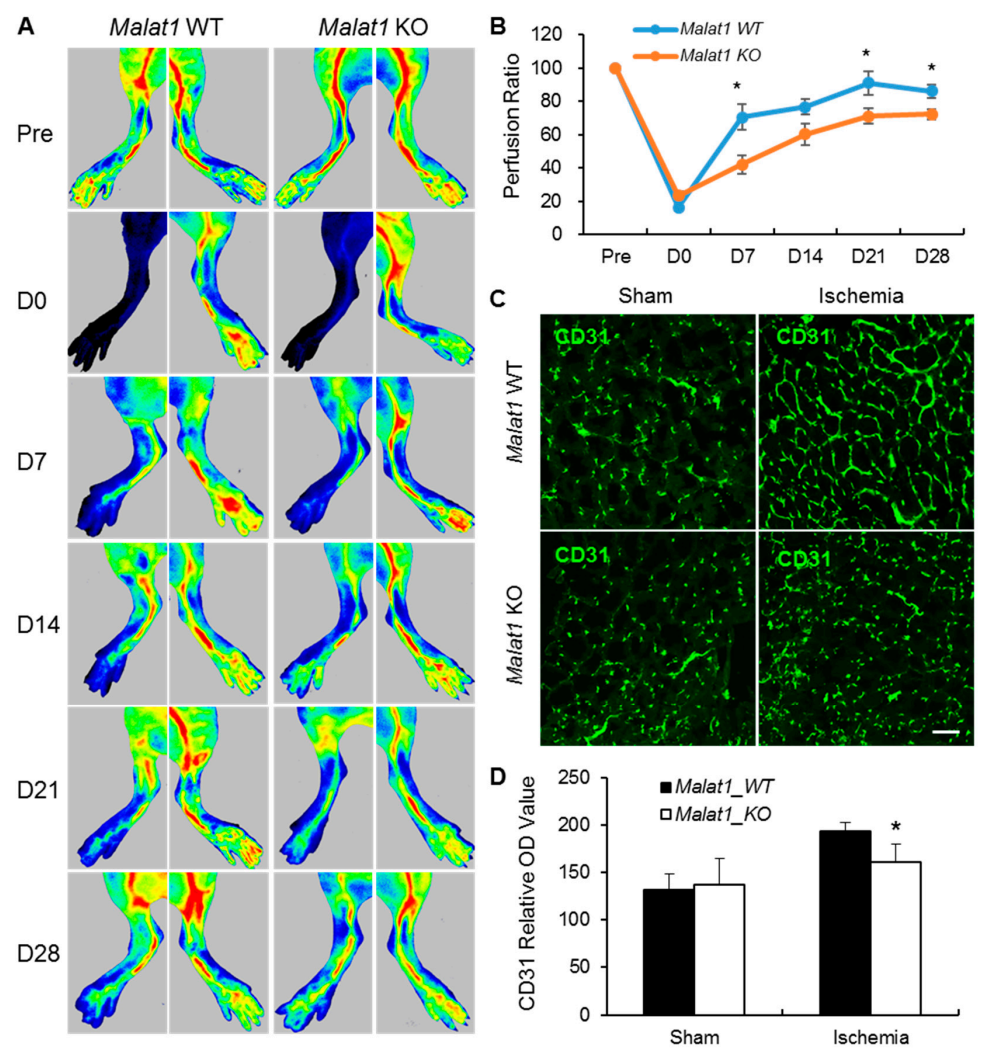

Figure 1. Effects of Malat1 genetic deficiency on local blood flow recovery after mouse hindlimb ischemia. (A,B) Malat1 knockout (Malat1 KO) and littermate control (Malat1 WT) mice were subjected to right femoral artery ligation and subsequently monitored by Laser Speckle imaging at days 0, 7, 14, 21, and 28 after hindlimb ischemia. The laser speckle pattern is visualized as a color-coded blood flow velocity with low flow = blue; high flow $=$ red. Representative images are shown in panel (A) and quantification of blood flow recovery is shown in panel (B) $(n=8$ per group). (C) Representative immunofluorescent images showing CD31-positive capillaries in transverse sections of non-ischemic (Sham-operated) and ischemic hindlimb gastrocnemius muscles from Malat1 WT and KO mice $(n=5)$. Green color indicates CD31-positive staining; and (D) Quantitative analysis of CD31-positive capillaries in panel (C). In comparison with Malat1 WT controls, genetic deficiency of Malat1 significantly delays blood flow recovery and reduces vascular density in hindlimbs following ischemic insults. Data are expressed as mean \pm SEM. ${ }^{*} p<0.05$ vs. Malat1 WT + ischemia group. Scale bar represents $50 \mu \mathrm{m}$. 


\subsection{Genetic Deficiency of Malat1 Decreased Pro-Angiogenic VEGFR2 Expression after Hindlimb Ischemia}

It has been largely accepted that VEGFR2 is the major mediator of angiogenic signaling in vascular endothelial cells and is required for angiogenesis [13]. Therefore, we examined VEGFR2 expression in ischemic hindlimb muscle at postoperative day 28 by immunofluorescence staining. The average VEGFR2 positive vessel-like structures were significantly decreased in ischemic hindlimbs of Malat1 KO mice compared with Malat1 WT controls (Figure 2A,B). The decreased VEGFR2 expression in Malat1 $\mathrm{KO}$ ischemic hindlimb muscle was also confirmed at the protein level by Western blotting (Figure 2C,D).
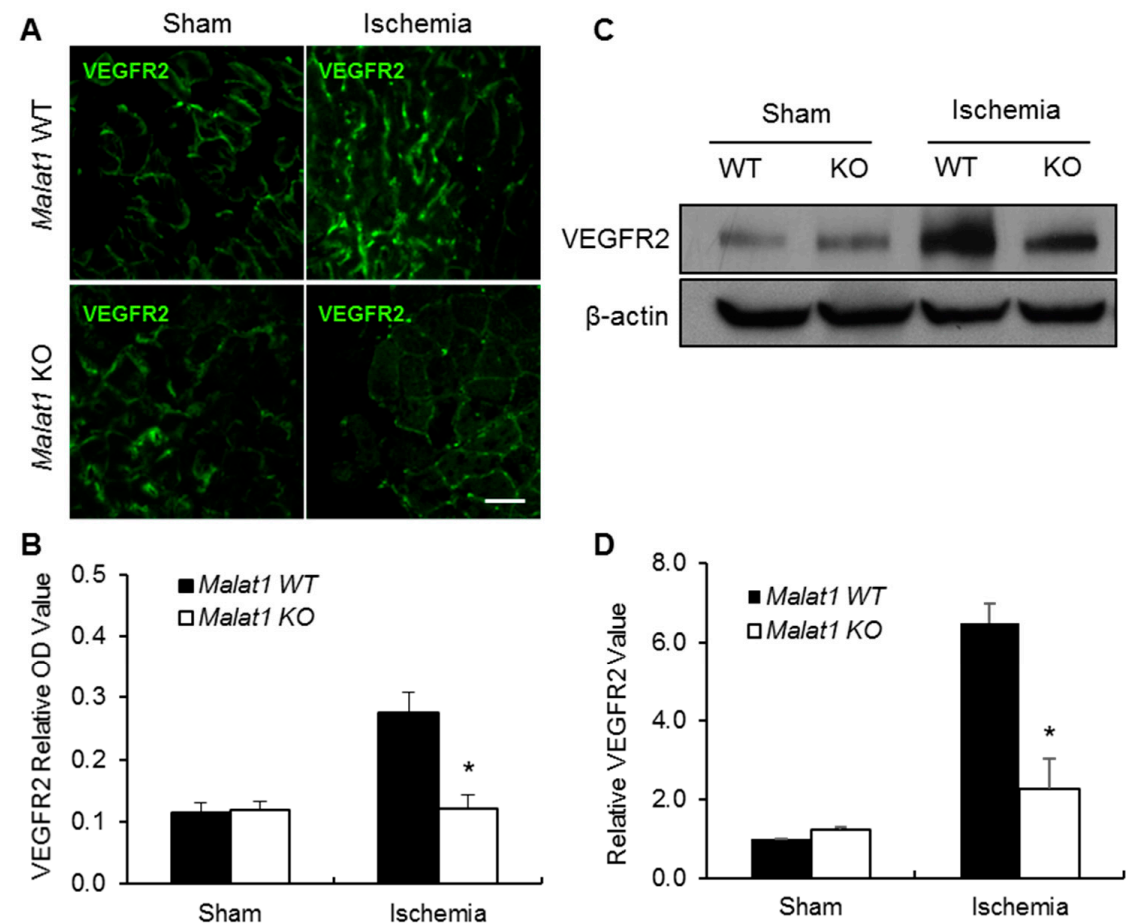

Figure 2. Genetic deletion of Malat1 gene attenuates VEGFR2 expression in ischemic hindlimb gastrocnemius muscles. (A) Representative immunofluorescent images showing VEGFR2-positive vessel-like structures in transverse sections of sham and ischemic hindlimb gastrocnemius muscles from Malat1 WT and Malat1 KO mice $(n=5)$; (B) Quantitative analysis of VEGFR2-positive staining in panel (A); (C) The protein levels of VEGFR2 were determined by Western blotting, with $\beta$-actin as the loading control; and (D) Quantitative analysis of VEGFR2 expression in sham and ischemic hindlimb gastrocnemius muscles from Malat1 WT and Malat1 KO mice. Experiments were repeated three times and representative blots are displayed. Data are expressed as mean \pm SEM. ${ }^{*} p<0.05$ vs. Malat1 WT + ischemia group. Scale bar represents $50 \mu \mathrm{m}$.

\subsection{Silencing of Malat1 Reduces Pro-Angiogenic VEGFR2 Expression in Mouse SMMEC Cultures}

To further uncover functional roles and molecular mechanisms of Malat1 on vascular endothelium in response to ischemic stimuli, mouse primary SMMECs were subjected to OGD for $16 \mathrm{~h}$, followed by $24 \mathrm{~h}$ reperfusion. We also employed single-stranded oligonucleotides Malat1 GapmeRs [33] as a genetic approach to achieve Malat1 silencing in mouse SMMEC cultures. Malat1 expression can be induced by ischemic stimuli [30-32,34]. As shown in Figure 3A, Malat1 displayed a five-fold increased expression after $16 \mathrm{~h}$ OGD exposure and kept at 2.5 -fold increased expression after $24 \mathrm{~h}$ reperfusion in SMMEC cultures (Figure 3A). The basal and OGD-induced Malat1 levels were significantly decreased by transfection with LNA-Malat1 GapmeR versus transfection with the Malat1 control in SMMEC cultures (Figure 3A). Treatment with Malat1 GapmeR also significantly decreased OGD-induced 
VEGFR2 expression at mRNA level when compared to the Malat1 control group (Figure 3B). Moreover, OGD-induced VEGFR2 level was significantly decreased by Malat1 GapmeR treatment at protein level by Western blotting (Figure 3C,D). The results suggest VEGFR2 as a downstream target of Malat1 in mouse vascular endothelial cells.

A

C

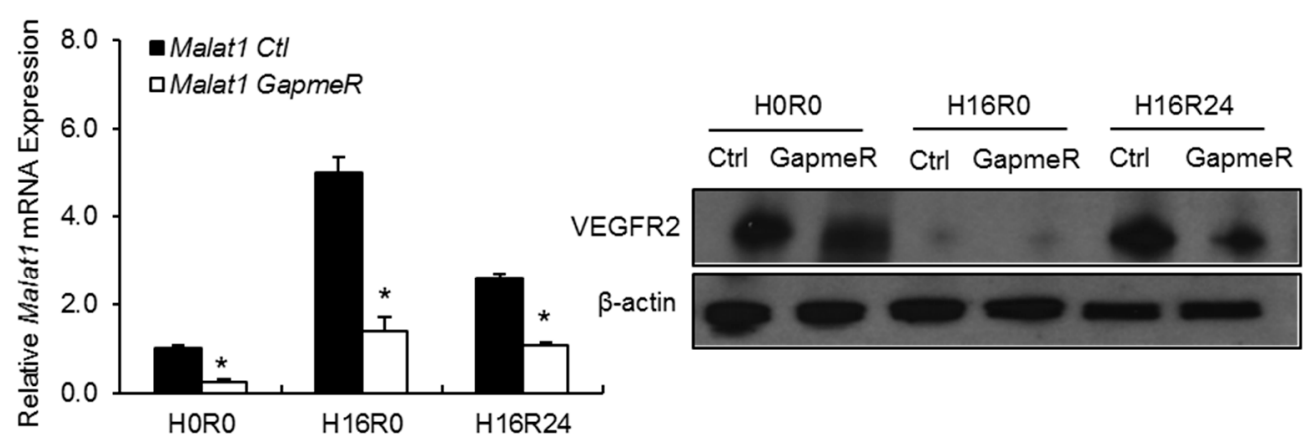

B

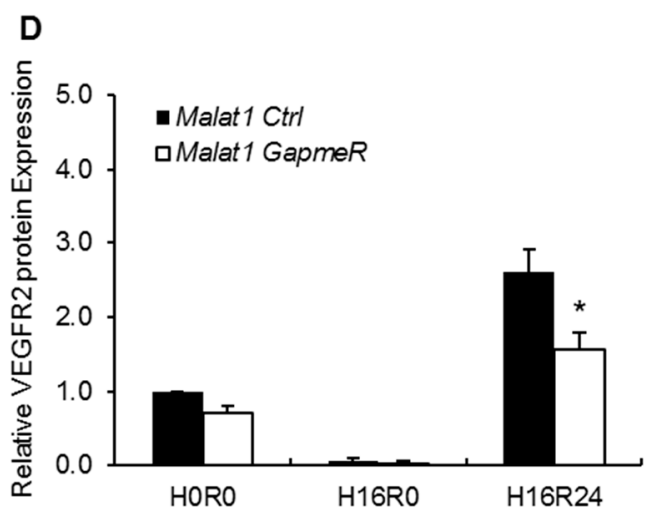

Figure 3. The effect of Malat1 silencing on VEGFR2 expression in mouse SMMECs after OGD and reperfusion. LNA-GapmeRs targeting Malat1 gene (Malat1 GapmeR) or scrambled control GapmeRs (Malat1 Ctrl) were transfected at $50 \mathrm{nM}$. (A) Malat1 and (B) VEGFR2 expression levels were examined by qPCR and normalized to Cyclophilin $(n=3)$. qPCR data showed significantly reduced Malat1 levels in Malat1 GapmeR group in the absence (H0R0) or presence of $16 \mathrm{~h}$ OGD exposure (H16R0) and $16 \mathrm{~h}$ OGD followed by $24 \mathrm{~h}$ reperfusion (H16R24); (C) The protein level of VEGFR2 was determined by Western blotting, with $\beta$-actin as the loading control; and (D) Quantitative analysis of VEGFR2 expression in Malat1 control and Malat1 GapmeR transfected SMMEC cells in H0R0, H16R0, and H16R24 groups. Experiments were repeated three times and representative blots are displayed. Data are expressed as mean \pm SEM. ${ }^{*} p<0.05$ vs. Malat1 Ctrl group.

\subsection{Malat1 Mediates SMMEC Cell Migration and Proliferation}

It has been accepted that endothelial cell migration is a crucial step in angiogenesis and cell invasion [35]. To further assess the regulatory effect of Malat1 to angiogenesis, in vitro scratch assays were performed in mouse SMMEC cultures following Malat1 control/GapmeR treatment. As shown in Figure 4, silencing of Malat1 in SMMECs markedly reduced cell migration in comparison with the Malat 1 control transfected group (Figure 4A,B). In addition, angiogenesis requires the proliferation of vascular endothelial cells; accordingly, we also tested whether silencing of Malat 1 affects SMMEC proliferation by using Bromodeoxyuridine (BrdU) incorporation assays. We found that Malat1 silencing in SMMECs effectively inhibited proliferation by reducing DNA synthesis $48 \mathrm{~h}$ and $72 \mathrm{~h}$ after GapmeR treatment (Figure 5A,B). Thus, our results suggest that Malat1 plays pro-angiogenic roles in SMMECs through modulating cell migration and proliferation. 


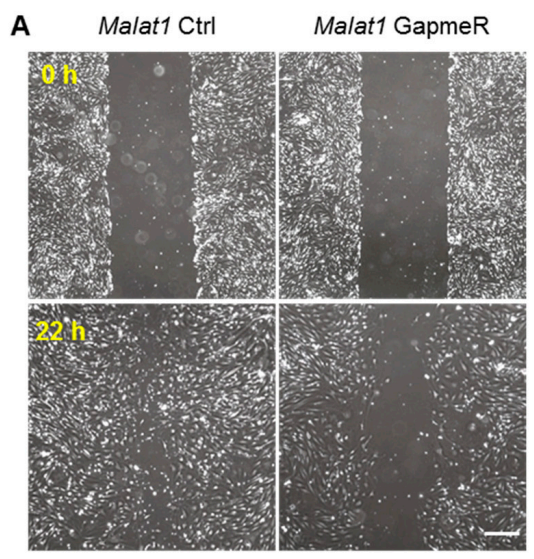

B

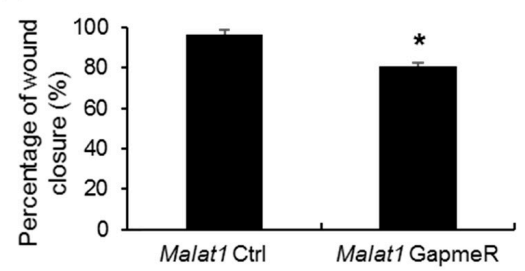

Figure 4. Malat1 silencing reduces cell migration in SMMECs. (A) Representative photomicrographs of in vitro wound healing assays. SMMCEs were transfected with either Malat1 control (Malat1 Ctrl) or Malat1 GapmeR for $48 \mathrm{~h}$ in 6-multiwell plates. Wounds were produced in SMMECs by a yellow pipet tip, and photomicrographs were taken as time $0 \mathrm{~h}$. After an additional $22 \mathrm{~h}$ of incubation, photomicrographs were taken again; and (B) Cellular migration was calculated by measuring the area occupied by the migrated cells. In comparison to Malat1 control (Malat1 Ctrl) group, Malat1 silencing by GapmeR treatment in SMMECs significantly damped cell migration. Results are mean \pm SEM of three independent experiments. ${ }^{*} p<0.05$ vs. Malat1 Ctrl group. Scale bar represents $100 \mu \mathrm{m}$.
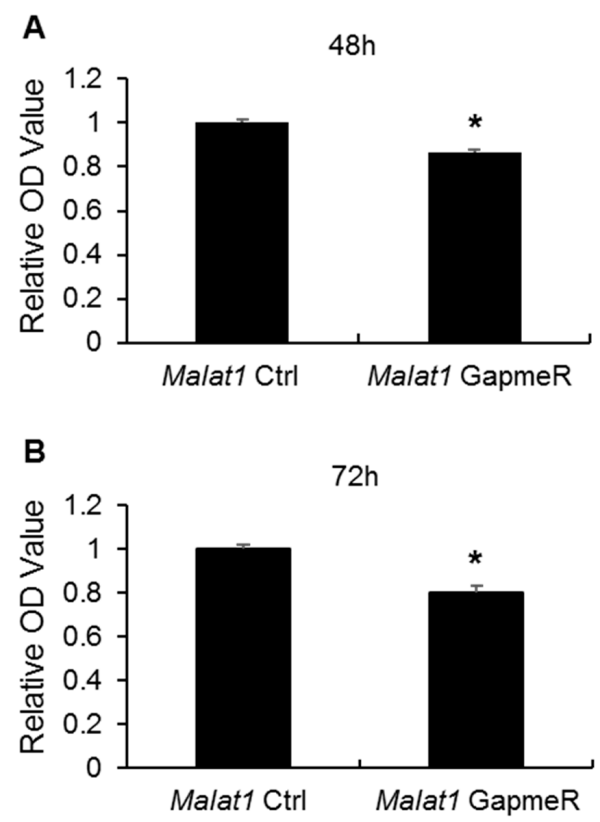

Figure 5. Effects of Malat1 silencing on cell proliferation. SMMECs were transfected with either Malat1 control (Malat1 Ctrl) or Malat1 GapmeR for (A) $48 \mathrm{~h}$ and (B) $72 \mathrm{~h}$. DNA synthesis was measured by BrdU incorporation assays as described in the Methods. The results are expressed as mean $\pm \mathrm{SEM}$ of three independent experiments. ${ }^{*} p<0.05$ vs. Malat1 Ctrl group. 


\subsection{Malat1 Regulates SMMEC Tube Formation}

To further define the molecular mechanisms of Malat1-mediated angiogenic activity after ischemic injury, we next analyzed the potential effect of Malat1 silencing on angiogenic activity in vitro by tube formation assays. Tube formation assay is known to mimic multiple key steps during angiogenic process, including endothelial cell adhesion, migration, differentiation, and growth [35]. Malat1 GapmeR treatment markedly attenuated angiogenic tube formation of SMMECs compared with Malat1 control group (Figure 6A), as quantitatively evaluated by number of branch points (Figure 6B) and total tube length (Figure 6C). Taken together, these results suggest that Malat1 directly regulates angiogenic activity in mouse SMMECs.
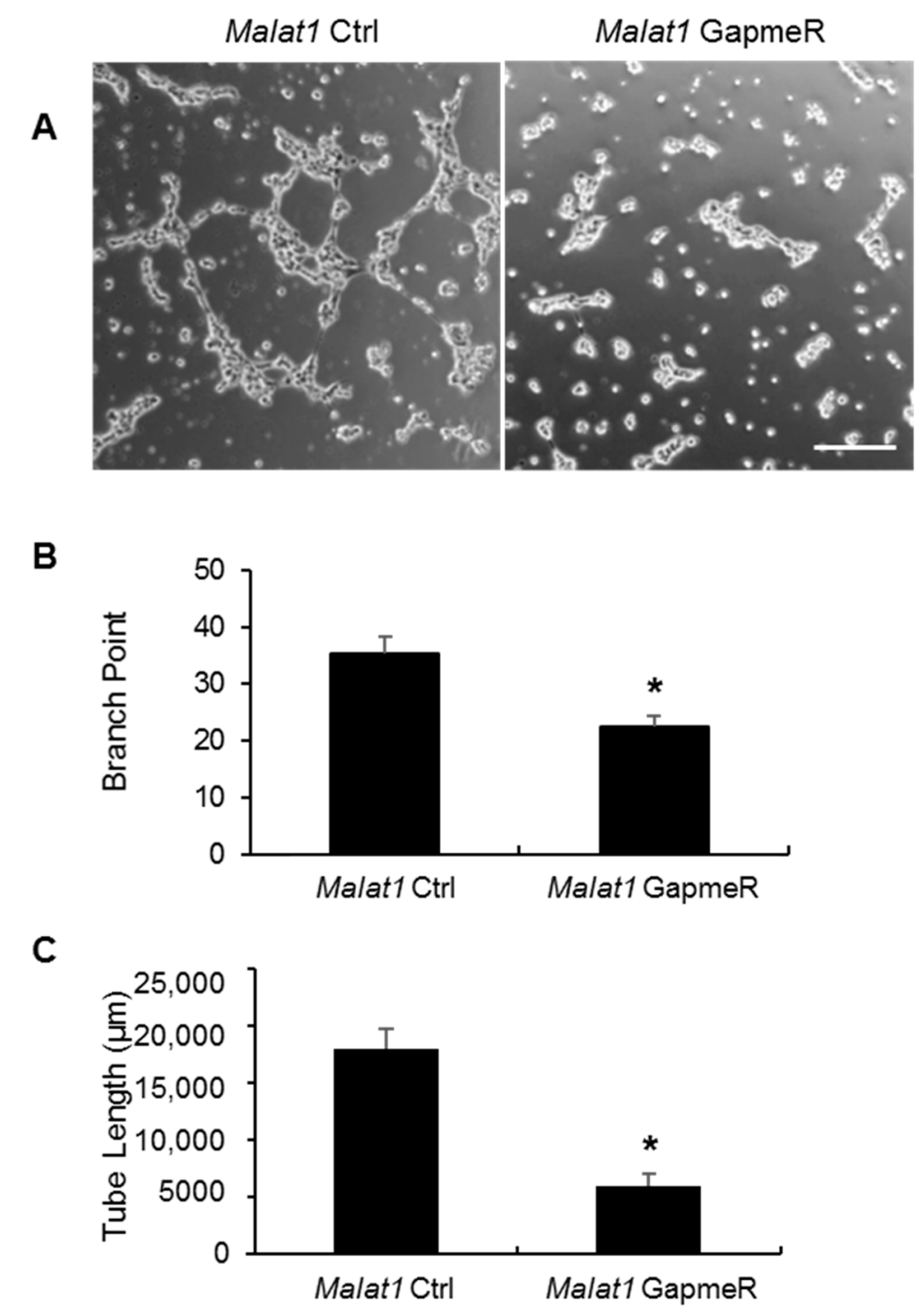

Figure 6. Effects of Malat1 silencing on tube formation. SMMECs were transfected with either Malat1 control (Malat1 Ctrl) or Malat1 GapmeR for $48 \mathrm{~h}$ and then treated with $1 \mathrm{ng} / \mu \mathrm{L}$ VEGF for $24 \mathrm{~h}$. The cells were then re-seeded in BD matrigel matrix-coated 24 -multiwell plates $\left(1 \times 10^{5}\right.$ cells/well $)$ in complete mouse endothelial cell medium (Cell Biologics, Chicago, IL, USA) for 6 h. (A) Representative photomicrographs of tubular structures. Images were quantified by $(B)$ counting the number of branch points and $(\mathbf{C})$ calculating total tube length in low power fields. Data are shown as mean \pm SEM of counted tube branch points and total tube length from six microscopic fields of three independent experiments. ${ }^{*} p<0.05$ vs. Malat1 Ctrl group. Scale bar represents $100 \mu \mathrm{m}$. 


\subsection{Malat1 Physically Binds to VEGFR2}

LncRNAs are known to exert biological effects by modulating gene expression and serve regulatory functions through sequence-specific hybridization and/or through structural and spatial mechanisms [36,37]. Malat1 predominantly localizes to nucleus under physiological condition [38-41]. Here we determined the subcellular distribution of Malat1 in mouse SMMECs by separating nuclear and cytoplasmic RNA fractions using a commercial kit. When we profiled Malat1 distribution in each fraction after 16h OGD exposure, we observed 2-fold enrichment of Malat1 in the cytoplasm (Figure 7A) and 1.5-fold enrichment of Malat1 in the nuclear (Figure 7B) compared with the non-OGD group. One of the most straightforward explanations for Malat1's regulatory effects on pro-angiogenic VEGFR2 is their physical association. Therefore, we performed RNA-immunoprecipitation (RIP) with VEGFR2 antibody from total extracts of OGD-treated mouse SMMEC cultures. We observed 6-fold enrichment of Malat1 in the VEGFR2 antibody immunoprecipitated SMMEC extracts compared with IgG control (Figure 7C). We also included two tight junction proteins claudin-5, and occludin in the RIP experiment, to serve as controls, as they have no interaction nor regulatory effects with Malat1. To confirm the physical interaction of Malat1 with VEGFR2 in vivo, we performed RIP with VEGFR2 antibody from fresh gastrocnemius muscle extracts of C57BL/6J mouse. Consistently, we observed 12-fold enrichment of Malat 1 in the VEGFR2 antibody immunoprecipitated extracts from gastrocnemius muscles compared with IgG control (Figure 7D). Taken together, the results indicate that Malat1 is physically associated with VEGFR2 in vitro and in vivo.

A

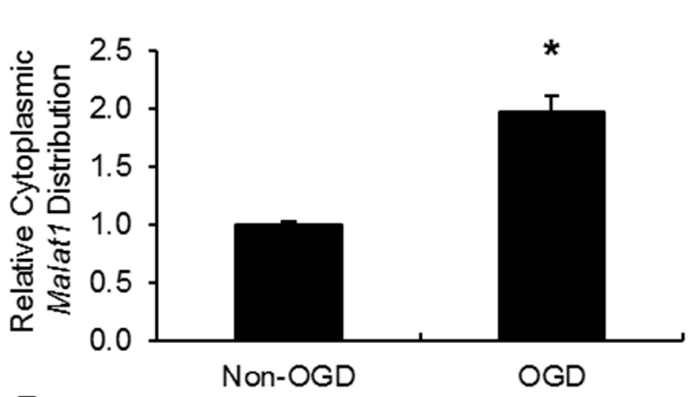

B

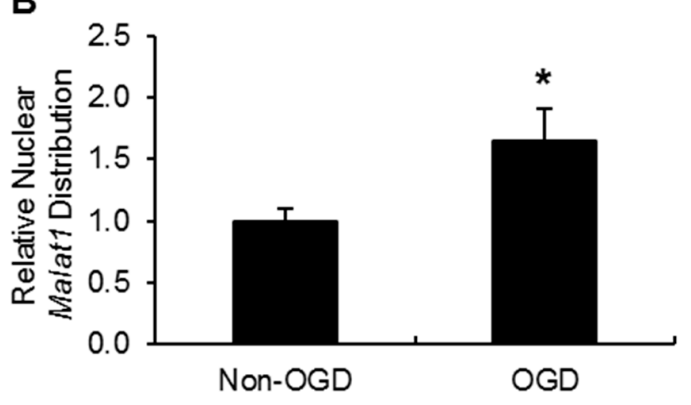

C

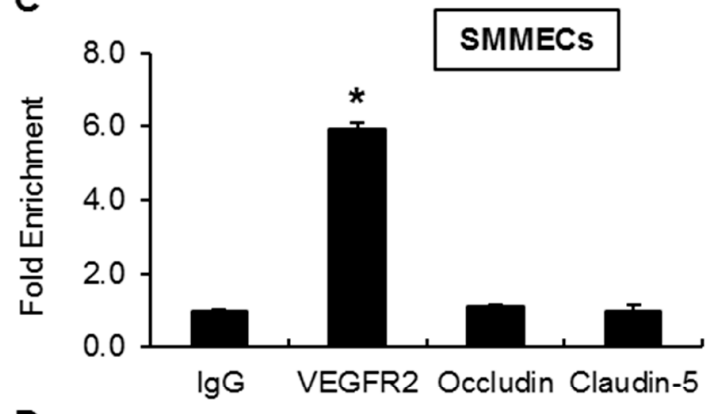

D

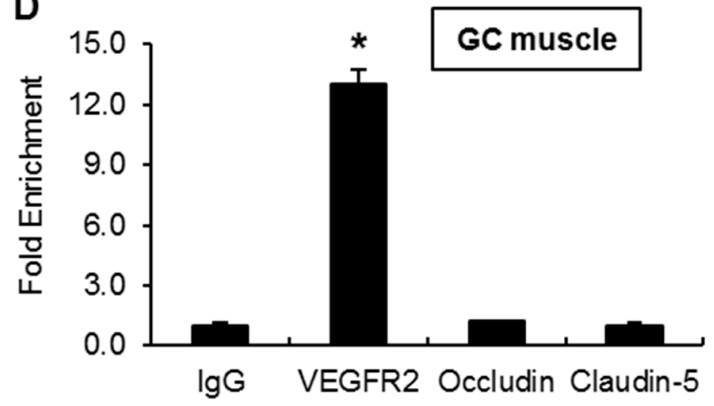

Figure 7. Malat1 physically associates with VEGFR2 in mouse-cultured SMMECs and mouse gastrocnemius muscles. (A,B) The subcellular localization of Malat1 was detected in mouse SMMEC cells. Nuclear, cytoplasmic, and total RNA were isolated from SMMEC cells with or without $16 \mathrm{~h}$ OGD treatment using the RNA Subcellular Isolation Kit (Active Motif, Carlsbad, CA, USA). Isolated RNAs were subjected to reverse transcription and qPCR analysis, with Malat1 from total RNA as endogenous control. (C,D) Interaction between Malat1 and VEGFR2 was revealed by RNA Immunoprecipitation. Total extracts of (C) cultured SMMECs and (D) mouse gastrocnemius muscles were immunoprecipitated with control IgG or anti-VEGFR2 antibody, and the complexes were analyzed for the presence of Malat1 by qPCR. Relative gene expression levels were calculated using the formula $2^{-\Delta C t}$ with $\Delta C_{\mathrm{t}}=C_{\mathrm{t}_{\text {(target) }}}-C_{\mathrm{t}_{\text {(control) }}}(n=3)$. Data are expressed as mean $\pm \mathrm{SEM}$ of two independent experiments with triplicate wells. ${ }^{*} p<0.05$ vs. IgG group. 


\section{Discussion}

In this study, we addressed the potential role and molecular mechanisms of lncRNA Malat1 in regulating cell-autonomous angiogenesis. We demonstrated that genetic deficiency of Malat1 led to a significantly lower recovery of local blood flow and decreased capillary density in mice following hindlimb ischemia. Moreover, LNA-GapmeR mediated silencing of Malat1 in skeletal muscle microvascular endothelial cells effectively reduced endothelial cell tube formation, migration, and proliferation. We further identified VEGFR2 as a direct downstream target of Malat1 through physical binding. The interaction between Malat1 and VEGFR2 is responsible for Malat1-mediated angiogenic effects after ischemic insults.

Malat1 was one of the first identified lncRNAs associated with human disease, which was originally described to be associated with metastasis of lung cancer [42]. It has been reported that Malat1 drives tumorigenesis through the promotion of tumor cell proliferation [43]. Moreover, overexpression of Malat1 results in increased cell migration in vitro [43]. Depletion of Malat1, on the other hand, inhibits cell motility in vitro and significantly limits metastasis formation in mouse cancer models $[43,44]$. In addition, Malat1 was reported to play an important role in tumor-driven angiogenesis through regulating vasculature formation and fibroblast growth factor 2 expression [34]. It has also been reported that Malat1 is involved in diabetes-induced microvascular dysfunction and regulates retinal endothelial cell proliferation, migration, and tube formation [29]. In another study, genetic deletion of Malat1 demonstrated reduced retinal vascular growth and endothelial growth [32]. However, the direct role of Malat1 on vascular endothelial cells in the setting of angiogenesis (cell-autonomous angiogenesis) has not been clearly identified despite its extensive expression in the vasculature.

In our in vivo experiments, genetic deficiency of Malat 1 appeared to significantly attenuate ischemia-induced angiogenesis, perfusion, and functional recovery of ischemic hindlimbs by impairing the expression of VEGFR2. In vitro studies using mouse primary skeletal muscle microvascular endothelial cells found that LNA-GapmeRs mediated Malat1 silencing resulted in significantly reduced EC tube formation, cell migration, and proliferation. Interestingly, although our in vivo results were in agreement with observations made by the Michalik group, i.e., that pharmacological inhibition of Malat1 significantly inhibited blood flow recovery in a mouse hindlimb ischemia model [32], our in vitro observations were slightly different. Both siRNA- and GapmeR-mediated silencing of Malat1 induced angiogenic sprouting but repressed proliferation of HUVEC cells [32]. On the other hand, the Liu group reported that siRNA-mediated Malat1 silencing significantly reduced vasculature formation capacity of HUVEC cells under both normoxic and hypoxic conditions [34]. In another study, siRNA-mediated silencing of Malat1-inhibited retinal endothelial cell migration and tube formation [29]. The discrepancy between two opposite in vitro observations could be due to different endothelial cell lines chosen for each in vitro study. Nonetheless, our results indicate that Malat1 silencing inhibited angiogenesis both in vivo and in vitro.

LncRNAs are predominantly located in the nucleus, and few are located in the cytoplasm [45]. Malat1 has been known as a nuclear-retained non-coding RNA [46]. The Michalik group determined the localization of several lncRNAs, including Malat1, in endothelial cells derived from various human vascular beds and found that Malat1 was highly enriched in the nuclear fraction [32]. The subcellular distribution of Malat1 in BMECs was determined in our previous study by in situ hybridization [30]. It appeared that Malat1 was predominantly localized in the nucleus, which is consistent with most other published studies in HeLa cells [47], lung cancer cells [44], and THP-1 cells [39]. However, several recent publications reported the presence of Malat1 in the cytoplasm to exert its function [48,49]. The Yang group profiled Malat1 distribution throughout the cell cycle [49]. Interestingly, they observed that Malat1 was partially translocated from the nucleus to the cytoplasm in the G2/M phase in synchronized HeLa cells, which contrasted to the unsynchronized cell populations in which Malat1 was localized predominantly in the nuclear portion. In our study, the subcellular distribution of Malat1 was determined using mouse SMMECs and the separation of nuclear and cytoplasmic fractions were 
made using a commercial kit. We observed $~ 2$-fold increased Malat1 expression in cytoplasmic fraction after $16 \mathrm{~h}$ OGD exposure when compared with Malat1 level in cytoplasmic fraction without OGD treatment, indicating that Malat1 subcellular distribution may be cell type-specific and varies under physiological and pathophysiological conditions.

The most straightforward explanation for Malat1 regulation of VEGFR2 is through physical interaction. Previous work by the Zhao group utilized RIP technique with the p65 antibody from subcellular extracts of LPS-stimulated THP-1 macrophages and observed $\sim 7$-fold enrichment of Malat1 in the anti-p65 immunoprecipitated cell extracts compared with the IgG control [39]. We also employed an RIP experiment in our study, and we observed $\sim 6$-fold enrichment of Malat1 in the anti-VEGFR2 immunoprecipitated extracts of OGD-treated SMMEC cultures and 20-fold enrichment of Malat1 in the anti-VEGFR2 immunoprecipitated gastrocnemius muscle extracts compared with IgG controls. This was the first study to document a direct physical association between Malat1 and VEGFR2 in vitro and in vivo.

The endothelium forms the central vascular barrier to maintain physiological vessel function and integrity. The angiogenic function of endothelial cells is strictly regulated by complex mechanisms, but the impact of IncRNAs has been less studied. Angiogenic response can be triggered under ischemic conditions such as ischemic stroke and myocardial infarction [6,50]. Post-ischemic angiogenesis plays a crucial role in the recovery of blood flow in ischemic tissues [51,52]. It has been reported that, in both stroke and heart attack patients, increased microvessel density has been observed in the penumbral areas, and the number of new angiogenic vessels is correlated with longer survival [53], suggesting active angiogenesis may be beneficial for neurological or cardiac functional recovery.

\section{Materials and Methods}

\subsection{Experimental Mice}

Malat1 knockout (Malat1 KO) mice on a C57BL/6J background were kindly provided by Dr. David L. Spector [28]. Generally, Malat1 KO mice are viable and fertile with normal appearance, behavior, growth, and litter size [26]. Animal studies were designed and performed following University of Pittsburgh Institutional Animal Care and Use Committee approved protocol (15096911, 22 June 2017).

\subsection{Mouse Model of Hindlimb Ischemia}

Eight-week-old female Malat1 KO and littermate control (Malat1 WT) mice were anesthetized with 1.5-3\% isoflurane (Henry Schein Animal Health, Melville, NY, USA). The right femoral artery was ligated and excised as described previously $[20,54,55]$. The mice were kept alive for four weeks to monitor local blood flow recovery and later subjected to histological analysis. A sham procedure was performed on the contralateral hindlimb to serve as the internal control.

\subsection{Laser Speckle Imaging (LSI) Measurement of Focal Blood Flow}

A laser speckle imager (Perimed PeriCam PSI HR, Stockholm, Sweden) was used to assess the recovery of local blood flow in mice after hindlimb ischemia procedure. Measurements were performed before surgery (Pre), immediately after surgery (D0), and postoperatively at days 7, 14, 21, and 28 . The hair was removed from the ventral hind limbs of the mice before laser scanning to minimize data variations. After three consecutive scans over the same region of interest (hind legs and feet) in each animal, the average blood flow values of ischemic and non-ischemic limbs were calculated by computer-assisted quantification. The perfusion index was determined as the ratio of ischemic to non-ischemic hindlimb blood flow [20]. 


\subsection{Analysis of Capillary Density}

Capillary densities were examined by counting the number of capillaries stained with anti-CD31 antibody. Ten different random microscopic fields on five different sections from each animal were photographed and analyzed by Image J (National Institutes of Health, Bethesda, MD, USA). Capillary density was expressed as number of capillaries per high-power field $(400 \times)$ as previously described [20].

\subsection{Immunofluorescent Staining and Confocal Imaging}

After completion of LSI, sham-operated and ischemic Malat1 WT and KO mice ( $n=5$ per group) were perfused with saline, and the gastrocnemius muscles were dissected out from both ischemic and contralateral hindlimb. Coronal sections $(8 \mu \mathrm{m})$ were cryosectioned for immunostaining with rat anti-CD31 (BD Pharmingen, San Diego, CA, USA 1:200) or rabbit anti-VEGFR2 antibody (Cell Signaling Technology, Danvers, MA, USA, 1:200). Secondary antibodies: Cy3-conjugated goat anti-rat IgG, Alexa Fluor 488-conjugated goat anti-rabbit IgG (all at 1:1000; Jackson ImmunoResearch Laboratories, Inc., West Grove, PA, USA). Images were collected on confocal microscope (FV1000-II; Olympus; Tokyo, Japan) and processed in Adobe Photoshop (CS2 version 9.0, Adobe Systems, San Jose, CA, USA) for compositions [56].

\subsection{Cell Cultures and Oxygen-Glucose Deprivation}

C57BL/6 mouse primary skeletal muscle microvascular endothelial cells (SMMEC) were purchased from Cell Biologics (C57-6220). Mouse SMMEC cells (2-6 passages) were grown to $85-95 \%$ confluency before use. To mimic ischemia-like conditions in vitro, mouse SMMEC cultures were exposed to OGD for $16 \mathrm{~h}$. In some experiments, mouse SMMECs were treated with $50 \mathrm{nM}$ Malat1 GapmeR (5'-3'/56-FAM/CGTTAACTAGGCTTTA) or Negative Control A (Malat1 Ctrl) (5'-3' /56-FAM/AACACGTCTATACGC) for $48 \mathrm{~h}$ prior to OGD exposure [26].

\subsection{Capillary Tube Formation Assay}

Malat1 Ctrl/GapmeR-treated SMMEC cells were seeded on Matrigel-coated 24-well plates $\left(1 \times 10^{5}\right.$ each well $)$ and incubated for $6 \mathrm{~h}$. Live cell images were collected using EVOS XL microscope (Waltham, MA, USA). Tube formation was analyzed by Image J and quantified by counting the number of branch points and calculating the total tube length in six randomly chosen fields from each well [20].

\subsection{In Vitro Scratch Assay}

SMMEC cells were transfected with either Malat1 Ctrl or Malat1 GapmeR for $48 \mathrm{~h}$ in 6-well plates. The SMMECs were scraped with a yellow pipet tip, and live cell images were collected using EVOS $\mathrm{XL}$ microscope at time $0 \mathrm{~h}$ and after $22 \mathrm{~h}$ incubation. Cell migration was calculated according to a published protocol [20,57].

\subsection{Bromodeoxyuridine (BrdU) Cell Proliferation Assay}

The effect of Malat1 silencing on cell proliferation was determined by BrdU cell proliferation assay (Millipore, Burlington, MA, USA, 2750). Briefly, SMMEC cells were transfected with either Malat1 control or Malat 1 GapmeR at $50 \mathrm{nM}$ for $48 \mathrm{~h}$ and $72 \mathrm{~h}$. The cells were then pulsed with BrdU reagents, and cell proliferation was measured by colorimetric immunoassays [20].

\subsection{Quantitative Real Time}

Total RNA was isolated from mouse SMMEC cultures or gastrocnemius muscle by using RNeasy Mini Kit (Qiagen, Valencia, CA, USA) or TRI reagent (Molecular Research Center, Inc., Cincinnati, OH, USA). Quantitative real-time reverse-transcriptase polymerase chain reaction (RT-PCR) was carried out with a Bio-Rad CFX Connect thermocycler, iScrip cDNA synthesis kit, and iTaq Universal SYBR green 
supermix (Bio-Rad, Hercules, CA, USA). Specific primers used for the reaction were as follows: Malat1 Forward, 5'-ggcggaattgctggtagttt-3'; Malat1 Reverse, 5'-agcatagcagtacacgcctt-3'. VEGFR2 Forward, 5'-tttggcaaatacaacccttcaga-3'; VEGFR2 Reverse, 5'-gcagaagatactgtcaccacc-3'. Cyclophilin Forward, 5'-actcctcatttagatgggcatca-3'; Cyclophilin Reverse, 5'-gagtatccgtacctccgcaaa-3'. The relative mRNA expression was normalized to Cyclophilin RNA levels. PCR experiments were repeated three times, each using separate sets of cultures [26].

\subsection{Western Blot}

Samples from the mouse SMMEC cultures or gastrocnemius muscle were homogenized in RIPA buffer (Thermo Scientific, Waltham, MA, USA), and total protein was isolated. Primary antibodies used were as follows: VEGFR2 (Cell Signaling Technology, Danvers, MA, USA, 1:1000) and $\beta$-actin (Sigma, Marlborough, MA, USA, 1:4000) [20,26].

\subsection{RNA Subcellular Isolation}

RNA subcellular isolation was performed using RNA Subcellular Isolation Kit (Active Motif, Carlsbad, CA, USA) according to the manufacturer's instruction. Briefly, mouse SMMEC cultures with or without $16 \mathrm{~h}$ OGD exposure were lysed in complete lysis buffer. The lysate was then separated by centrifugation, with the supernatant containing cytoplasmic RNA and the pellet containing nuclear RNA. A guanidine-based buffer and ethanol were added to each RNA fraction before being loaded onto spin-columns. The RNA fractions were washed, eluted and quantified. Purified RNAs from each fraction were analyzed by qPCR using primers specific for Malat1. The relative cytoplasmic Malat1 level was normalized to Malat1 from total RNA extract.

\subsection{RNA Immunoprecipitation}

RNA immunoprecipitation (RIP) was performed using the Magna RIP RNA-Binding Protein Immunoprecipitation Kit (Millipore) as previously described [30]. Anti-VEGFR2 (Cell Signaling Technology) antibody was used for RIP. Co-precipitated RNAs from total extracts of mouse SMMEC cultures or mouse gastrocnemius muscle were analyzed by qPCR using primers specific for Malat1. Total RNA (input control) and the isotype control were assayed simultaneously to show the binding specificity between Malat1 and VEGFR2.

\subsection{Statistical Analysis}

Quantitative data are expressed as mean \pm SEM based on at least three independent experiments of triplicate samples. Differences among three or more groups were statistically analyzed by one-way analysis of variance followed by Bonferroni's post-hoc test. Comparisons between two experimental groups were based on a two-tailed $t$ test. A $p$-value less than 0.05 was considered significant.

\section{Conclusions}

Using genetically manipulated animal model and antisense LNA GapmeRs, our present findings suggest that Malat1 regulates post-ischemic angiogenesis via interaction with VEGFR2. The findings will lead us to better understand the mechanisms of LncRNA-mediated regulation of angiogenesis and establish a human translational basis for the development of novel restorative therapy to enhance functional recovery following ischemic cerebrovascular and cardiovascular diseases.

Author Contributions: X.Z. conducted most of the experiments, analyzed the results, and wrote the paper. X.T. conducted experiments on hindlimb ischemia model and blood flow measurement. M.H.H., and K.-J.Y. revised the manuscript and helped with language editing.

Acknowledgments: This work was supported by the National Institute of Health Grants: NS094930, NS091175, NS086820 (Ke-Jie Yin). We thank David L. Spector at Cold Spring Harbor Laboratory for kindly providing us Malat1 KO mice. 
Conflicts of Interest: The authors declare no conflict of interest.

\section{References}

1. Carmeliet, P. Angiogenesis in health and disease. Nat. Med. 2003, 9, 653-660. [CrossRef] [PubMed]

2. Fischer, C.; Schneider, M.; Carmeliet, P. Principles and therapeutic implications of angiogenesis, vasculogenesis and arteriogenesis. Handb. Exp. Pharmacol. 2006, 176, 157-212.

3. Hanahan, D.; Weinberg, R.A. Hallmarks of cancer: The next generation. Cell 2011, 144, 646-674. [CrossRef] [PubMed]

4. Carmeliet, P. Angiogenesis in life, disease and medicine. Nature 2005, 438, 932-936. [CrossRef] [PubMed]

5. Zhang, X.; Nie, D.; Chakrabarty, S. Growth factors in tumor microenvironment. Front. Biosci. 2010, 15, 151-165. [CrossRef]

6. Yanagisawa-Miwa, A.; Uchida, Y.; Nakamura, F.; Tomaru, T.; Kido, H.; Kamijo, T.; Sugimoto, T.; Kaji, K.; Utsuyama, M.; Kurashima, C.; et al. Salvage of infarcted myocardium by angiogenic action of basic fibroblast growth factor. Science 1992, 257, 1401-1403. [CrossRef] [PubMed]

7. Kumar, M.M.; Goyal, R. LncRNA as a therapeutic target for angiogenesis. Curr. Top. Med. Chem. 2017, 17, 1750-1757. [CrossRef] [PubMed]

8. Ballmer-Hofer, K.; Andersson, A.E.; Ratcliffe, L.E.; Berger, P. Neuropilin-1 promotes vegfr-2 trafficking through rab11 vesicles thereby specifying signal output. Blood 2011, 118, 816-826. [CrossRef] [PubMed]

9. Cross, M.J.; Claesson-Welsh, L. FGF and VEGF function in angiogenesis: Signalling pathways, biological responses and therapeutic inhibition. Trends Pharmacol. Sci. 2001, 22, 201-207. [CrossRef]

10. Martiny-Baron, G.; Marme, D. VEGF-mediated tumour angiogenesis: A new target for cancer therapy. Curr. Opin. Biotechnol. 1995, 6, 675-680. [CrossRef]

11. Olsson, A.K.; Dimberg, A.; Kreuger, J.; Claesson-Welsh, L. VEGF receptor signalling-in control of vascular function. Nat. Rev. Mol. Cell. Biol. 2006, 7, 359-371. [CrossRef] [PubMed]

12. Brogi, E.; Wu, T.; Namiki, A.; Isner, J.M. Indirect angiogenic cytokines upregulate VEGF and BFGF gene expression in vascular smooth muscle cells, whereas hypoxia upregulates vegf expression only. Circulation 1994, 90, 649-652. [CrossRef] [PubMed]

13. Shalaby, F.; Rossant, J.; Yamaguchi, T.P.; Gertsenstein, M.; Wu, X.F.; Breitman, M.L.; Schuh, A.C. Failure of blood-island formation and vasculogenesis in flk-1-deficient mice. Nature 1995, 376, 62-66. [CrossRef] [PubMed]

14. Bartel, D.P.; Chen, C.Z. Micromanagers of gene expression: The potentially widespread influence of metazoan microRNAs. Nat. Rev. Genet. 2004, 5, 396-400. [CrossRef] [PubMed]

15. Ponting, C.P.; Oliver, P.L.; Reik, W. Evolution and functions of long noncoding RNAs. Cell 2009, 136, 629-641. [CrossRef] [PubMed]

16. Cesana, M.; Cacchiarelli, D.; Legnini, I.; Santini, T.; Sthandier, O.; Chinappi, M.; Tramontano, A.; Bozzoni, I. A long noncoding RNA controls muscle differentiation by functioning as a competing endogenous RNA. Cell 2011, 147, 358-369. [CrossRef] [PubMed]

17. Grote, P.; Herrmann, B.G. Long noncoding RNAs in organogenesis: Making the difference. Trends Genet. 2015, 31, 329-335. [CrossRef] [PubMed]

18. Nagano, T.; Fraser, P. No-nonsense functions for long noncoding RNAs. Cell 2011, 145, 178-181. [CrossRef] [PubMed]

19. Kanduri, C. Long noncoding RNAs: Lessons from genomic imprinting. Biochim. Biophys. Acta 2016, 1859, 102-111. [CrossRef] [PubMed]

20. Yin, K.J.; Olsen, K.; Hamblin, M.; Zhang, J.; Schwendeman, S.P.; Chen, Y.E. Vascular endothelial cell-specific microRNA-15a inhibits angiogenesis in hindlimb ischemia. J. Biol. Chem. 2012, 287, 27055-27064. [CrossRef] [PubMed]

21. Wang, S.; Olson, E.N. Angiomirs-Key regulators of angiogenesis. Curr. Opin. Genet. Dev. 2009, 19, $205-211$. [CrossRef] [PubMed]

22. Gordon, F.E.; Nutt, C.L.; Cheunsuchon, P.; Nakayama, Y.; Provencher, K.A.; Rice, K.A.; Zhou, Y.; Zhang, X.; Klibanski, A. Increased expression of angiogenic genes in the brains of mouse meg3-null embryos. Endocrinology 2010, 151, 2443-2452. [CrossRef] [PubMed] 
23. Fu, W.M.; Lu, Y.F.; Hu, B.G.; Liang, W.C.; Zhu, X.; Yang, H.D.; Li, G.; Zhang, J.F. Long noncoding RNA hotair mediated angiogenesis in nasopharyngeal carcinoma by direct and indirect signaling pathways. Oncotarget 2016, 7, 4712-4723. [CrossRef] [PubMed]

24. Kurian, L.; Aguirre, A.; Sancho-Martinez, I.; Benner, C.; Hishida, T.; Nguyen, T.B.; Reddy, P.; Nivet, E.; Krause, M.N.; Nelles, D.A.; et al. Identification of novel long noncoding RNAs underlying vertebrate cardiovascular development. Circulation 2015, 131, 1278-1290. [CrossRef] [PubMed]

25. Leisegang, M.S.; Fork, C.; Josipovic, I.; Richter, F.M.; Preussner, J.; Hu, J.; Miller, M.J.; Epah, J.; Hofmann, P.; Gunther, S.; et al. Long noncoding RNA mantis facilitates endothelial angiogenic function. Circulation 2017, 136, 65-79. [CrossRef] [PubMed]

26. Zhang, X.; Hamblin, M.H.; Yin, K.J. The long noncoding RNA Malat1: Its physiological and pathophysiological functions. RNA Biol. 2017, 14, 1705-1714. [CrossRef] [PubMed]

27. Wilusz, J.E. Long noncoding RNAs: Re-writing dogmas of RNA processing and stability. Biochim. Biophys. Acta 2016, 1859, 128-138. [CrossRef] [PubMed]

28. Zhang, B.; Arun, G.; Mao, Y.S.; Lazar, Z.; Hung, G.; Bhattacharjee, G.; Xiao, X.; Booth, C.J.; Wu, J.; Zhang, C.; et al. The IncRNA Malat1 is dispensable for mouse development but its transcription plays a cis-regulatory role in the adult. Cell Rep. 2012, 2, 111-123. [CrossRef] [PubMed]

29. Liu, J.Y.; Yao, J.; Li, X.M.; Song, Y.C.; Wang, X.Q.; Li, Y.J.; Yan, B.; Jiang, Q. Pathogenic role of lncRNA-Malat1 in endothelial cell dysfunction in diabetes mellitus. Cell Death Dis. 2014, 5, e1506. [CrossRef] [PubMed]

30. Zhang, X.; Tang, X.; Liu, K.; Hamblin, M.H.; Yin, K.J. Long non-coding RNA Malat1 regulates cerebrovascular pathologies in ischemic stroke. J. Neurosci. 2017, 37, 1797-1806. [CrossRef] [PubMed]

31. Zhang, J.; Yuan, L.; Zhang, X.; Hamblin, M.H.; Zhu, T.; Meng, F.; Li, Y.; Chen, Y.E.; Yin, K.J. Altered long non-coding RNA transcriptomic profiles in brain microvascular endothelium after cerebral ischemia. Exp. Neurol. 2016, 277, 162-170. [CrossRef] [PubMed]

32. Michalik, K.M.; You, X.; Manavski, Y.; Doddaballapur, A.; Zornig, M.; Braun, T.; John, D.; Ponomareva, Y.; Chen, W.; Uchida, S.; et al. Long noncoding RNA Malat1 regulates endothelial cell function and vessel growth. Circ. Res. 2014, 114, 1389-1397. [CrossRef] [PubMed]

33. Dullea, R.; Salatto, C.; Sciabola, S.; Chen, T.; Dimattia, D.; Gandhok, H.; Kreeger, J.; Weng, Y.; Clark, T.; Vage, C.; et al. Study of CRTC2 pharmacology using antisense oligonuceotides. Nucleic Acid Ther. 2014, 24, 127-138. [CrossRef] [PubMed]

34. Tee, A.E.; Liu, B.; Song, R.; Li, J.; Pasquier, E.; Cheung, B.B.; Jiang, C.; Marshall, G.M.; Haber, M.; Norris, M.D.; et al. The long noncoding RNA Malat1 promotes tumor-driven angiogenesis by up-regulating pro-angiogenic gene expression. Oncotarget 2016, 7, 8663-8675. [CrossRef] [PubMed]

35. Arnaoutova, I.; George, J.; Kleinman, H.K.; Benton, G. The endothelial cell tube formation assay on basement membrane turns 20: State of the science and the art. Angiogenesis 2009, 12, 267-274. [CrossRef] [PubMed]

36. Zhao, J.; Ohsumi, T.K.; Kung, J.T.; Ogawa, Y.; Grau, D.J.; Sarma, K.; Song, J.J.; Kingston, R.E.; Borowsky, M.; Lee, J.T. Genome-wide identification of polycomb-associated RNAs by rip-seq. Mol. Cell 2010, 40, 939-953. [CrossRef] [PubMed]

37. Mercer, T.R.; Dinger, M.E.; Mattick, J.S. Long non-coding RNAs: Insights into functions. Nat. Rev. Genet. 2009, 10, 155-159. [CrossRef] [PubMed]

38. Eissmann, M.; Gutschner, T.; Hammerle, M.; Gunther, S.; Caudron-Herger, M.; Gross, M.; Schirmacher, P.; Rippe, K.; Braun, T.; Zornig, M.; et al. Loss of the abundant nuclear non-coding RNA Malat1 is compatible with life and development. RNA Biol. 2012, 9, 1076-1087. [CrossRef] [PubMed]

39. Zhao, G.; Su, Z.; Song, D.; Mao, Y.; Mao, X. The long noncoding RNA Malat1 regulates the lipopolysaccharideinduced inflammatory response through its interaction with nf-kappab. FEBS Lett. 2016, 590, 2884-2895. [CrossRef] [PubMed]

40. Hutchinson, J.N.; Ensminger, A.W.; Clemson, C.M.; Lynch, C.R.; Lawrence, J.B.; Chess, A. A screen for nuclear transcripts identifies two linked noncoding RNAs associated with sc35 splicing domains. BMC Genom. 2007, 8, 39. [CrossRef] [PubMed]

41. Bernard, D.; Prasanth, K.V.; Tripathi, V.; Colasse, S.; Nakamura, T.; Xuan, Z.; Zhang, M.Q.; Sedel, F.; Jourdren, L.; Coulpier, F.; et al. A long nuclear-retained non-coding RNA regulates synaptogenesis by modulating gene expression. EMBO J. 2010, 29, 3082-3093. [CrossRef] [PubMed] 
42. Ji, P.; Diederichs, S.; Wang, W.; Boing, S.; Metzger, R.; Schneider, P.M.; Tidow, N.; Brandt, B.; Buerger, H.; Bulk, E.; et al. Malat-1, a novel noncoding RNA, and thymosin beta4 predict metastasis and survival in early-stage non-small cell lung cancer. Oncogene 2003, 22, 8031-8041. [CrossRef] [PubMed]

43. Schmidt, L.H.; Spieker, T.; Koschmieder, S.; Schaffers, S.; Humberg, J.; Jungen, D.; Bulk, E.; Hascher, A.; Wittmer, D.; Marra, A.; et al. The long noncoding malat-1 RNA indicates a poor prognosis in non-small cell lung cancer and induces migration and tumor growth. J. Thorac. Oncol. 2011, 6, 1984-1992. [CrossRef] [PubMed]

44. Tano, K.; Mizuno, R.; Okada, T.; Rakwal, R.; Shibato, J.; Masuo, Y.; Ijiri, K.; Akimitsu, N. Malat-1 enhances cell motility of lung adenocarcinoma cells by influencing the expression of motility-related genes. FEBS Lett. 2010, 584, 4575-4580. [CrossRef] [PubMed]

45. Lennox, K.A.; Behlke, M.A. Cellular localization of long non-coding RNAs affects silencing by RNAi more than by antisense oligonucleotides. Nucleic Acids Res. 2016, 44, 863-877. [CrossRef] [PubMed]

46. Wilusz, J.E.; Freier, S.M.; Spector, D.L. 3’ end processing of a long nuclear-retained noncoding RNA yields a tRNA-like cytoplasmic RNA. Cell 2008, 135, 919-932. [CrossRef] [PubMed]

47. Tripathi, V.; Ellis, J.D.; Shen, Z.; Song, D.Y.; Pan, Q.; Watt, A.T.; Freier, S.M.; Bennett, C.F.; Sharma, A.; Bubulya, P.A.; et al. The nuclear-retained noncoding RNA Malat1 regulates alternative splicing by modulating sr splicing factor phosphorylation. Mol. Cell 2010, 39, 925-938. [CrossRef] [PubMed]

48. Dodd, D.W.; Gagnon, K.T.; Corey, D.R. Digital quantitation of potential therapeutic target RNAs. Nucleic Acid Ther. 2013, 23, 188-194. [CrossRef] [PubMed]

49. Yang, F.; Yi, F.; Han, X.; Du, Q.; Liang, Z. Malat-1 interacts with hnrnp c in cell cycle regulation. FEBS Lett. 2013, 587, 3175-3181. [CrossRef] [PubMed]

50. Zhang, Z.G.; Zhang, L.; Jiang, Q.; Zhang, R.; Davies, K.; Powers, C.; Bruggen, N.; Chopp, M. Vegf enhances angiogenesis and promotes blood-brain barrier leakage in the ischemic brain. J. Clin. Invest. 2000, 106, 829-838. [CrossRef] [PubMed]

51. Hayashi, T.; Deguchi, K.; Nagotani, S.; Zhang, H.; Sehara, Y.; Tsuchiya, A.; Abe, K. Cerebral ischemia and angiogenesis. Curr. Neurovasc. Res. 2006, 3, 119-129. [CrossRef] [PubMed]

52. Arai, K.; Jin, G.; Navaratna, D.; Lo, E.H. Brain angiogenesis in developmental and pathological processes: Neurovascular injury and angiogenic recovery after stroke. FEBS J. 2009, 276, 4644-4652. [CrossRef] [PubMed]

53. Krupinski, J.; Kaluza, J.; Kumar, P.; Kumar, S.; Wang, J.M. Some remarks on the growth-rate and angiogenesis of microvessels in ischemic stroke. Morphometric and immunocytochemical studies. Patol. Pol. 1993, 44, 203-209. [PubMed]

54. Couffinhal, T.; Silver, M.; Zheng, L.P.; Kearney, M.; Witzenbichler, B.; Isner, J.M. Mouse model of angiogenesis. Am. J. Pathol. 1998, 152, 1667-1679. [PubMed]

55. Limbourg, A.; Korff, T.; Napp, L.C.; Schaper, W.; Drexler, H.; Limbourg, F.P. Evaluation of postnatal arteriogenesis and angiogenesis in a mouse model of hind-limb ischemia. Nat. Protoc. 2009, 4, 1737-1746. [CrossRef] [PubMed]

56. Dong, W.; Zhang, X.; Liu, W.; Chen, Y.J.; Huang, J.; Austin, E.; Celotto, A.M.; Jiang, W.Z.; Palladino, M.J.; Jiang, Y.; et al. A conserved polybasic domain mediates plasma membrane targeting of Lgl and its regulation by hypoxia. J. Cell Biol. 2015, 211, 273-286. [CrossRef] [PubMed]

57. Liang, C.C.; Park, A.Y.; Guan, J.L. In vitro scratch assay: A convenient and inexpensive method for analysis of cell migration in vitro. Nat. Protoc. 2007, 2, 329-333. [CrossRef] [PubMed]

(C) 2018 by the authors. Licensee MDPI, Basel, Switzerland. This article is an open access article distributed under the terms and conditions of the Creative Commons Attribution (CC BY) license (http://creativecommons.org/licenses/by/4.0/). 